\title{
Explore the correlation between cerebral vessel characteristics with cognitive impairment among elder individuals: a community study from China
}

\author{
Wei-Wen Wu ${ }^{1 *}$, Yang Wang ${ }^{1}$, Jun $\mathrm{Xu}^{2}$, Li-Xia Lu' ${ }^{1}$ Lin Chen ${ }^{1}$, Gang Wu ${ }^{2}$ and Hui Yu ${ }^{1}$
}

\begin{abstract}
Background: Brain Magnetic Resonance Imaging (MRI) examination of cerebral small vessel disease (CSVD) may help screen vascular cognitive impairment. A recently estimated CSVD score system was suggested to capture the overall CSVD burden. The study aimed to detect the association between systemic evaluation score of cerebral vascular imaging parameters with cognitive functions.

Methods: This was a cross-sectional study in community settings. From October 2017 to September 2018, elder ( $\geqq 60$ ) residents were recruited through on-site visit in 6 communities from Shanghai, China. The participants underwent brain MRl, carotid ultrasound, laboratory tests of blood and urine samples. Cognitive function was evaluated using Mini-Mental State Examination (MMSE). MRI score of CSVD was calculated according to the 2012 standard for the evaluation of statistical changes in imaging.

Results: Total 171 subjects completed survey and examinations. There were 55 participants diagnosed with cognitive impairment, with a total percentage of 32.2\%. Participants with and without cognitive impairment showed significant differences in age, BMl and education level. Cognitive impaired participant had more disease history/comorbidity of hypertension and chronic renal insufficiency, higher level of creatinine, as well as lower level of full blood count (FBC) and alanine aminotransferase (ALT). A significant difference was detected in CSVD score between participants with and without cognitive impairment. Results of linear regression analysis showed significant negative correlations between MMSE score and both left and right carotid artery peak systolic velocity (PSV), however the CSVD score was only borderline $(P=0.0566)$ positively correlated with MMSE. Multivariate linear correlation analysis including all collected risk factor data showed that left carotid artery PSV score was among the independent negative correlated factors of MMSE. Multivariate binary logistic analysis showed that age, education and history of hypertension were the only statistically associated factors of cognitive impairment.
\end{abstract}

Conclusions: The current study identified high prevalence of cognitive impairment in a Chinese community. In addition, correlations between cerebral vascular disease imaging status and cognitive functions were confirmed although the sample size limited the possibility of screening cognitive impairment with imaging technique.

Keywords: Vascular dementia, Cerebral MRI, CSVD score, Left carotid artery peak systolic velocity (PSV), MMSE

\footnotetext{
*Correspondence: weiwenwu0609@163.com

1 Department of Neurology, Qingpu Branch of Zhongshan Hospital,

Fudan University, 1158 Park East Road, Qingpu Town, Qingpu District,

Shanghai 201700, China

Full list of author information is available at the end of the article
}

(C) The Author(s) 2021. Open Access This article is licensed under a Creative Commons Attribution 4.0 International License, which permits use, sharing, adaptation, distribution and reproduction in any medium or format, as long as you give appropriate credit to the original author(s) and the source, provide a link to the Creative Commons licence, and indicate if changes were made. The images or other third party material in this article are included in the article's Creative Commons licence, unless indicated otherwise in a credit line to the material. If material is not included in the article's Creative Commons licence and your intended use is not permitted by statutory regulation or exceeds the permitted use, you will need to obtain permission directly from the copyright holder. To view a copy of this licence, visit http://creativecommons.org/licenses/by/4.0/. The Creative Commons Public Domain Dedication waiver (http://creativeco mmons.org/publicdomain/zero/1.0/) applies to the data made available in this article, unless otherwise stated in a credit line to the data. 


\section{Background}

Dementia is progressive disease in mental health that may lead to compromised capability of independent living. The population affected by dementia was estimated to be 50 million worldwide in 2018 and the number was anticipated to be tripled by 2050 [1]. The disease causes health concerns as well as great economic burden in society. Aging was the most important risk factor of dementia and senile cognitive impairment has emerged as one of the major public health challenges [2]. Mild cognitive impairment $(\mathrm{MCI})$ represents an intermediate state between normal cognition and dementia, and could be a precursor to dementia [3]. Once diagnosed with MCI, individuals are subjected to markedly higher risk for worsening in several years [4]. Medical attention on persons with cognitive impairment and dementia are critical due to their significant care needs. It is anticipated that the cost due to dementia will approach $\$ 4$ trillion [5].

Vascular etiology, behind Alzheimer's disease (AD), is the second most common cause of dementia associated with age, and probably the predominant cause of cognitive impairment in East Asia [6, 7]. Vascular disorder, especially those affect small cerebral vessels, may also participate in cognitive dysfunction due to other pathologies, including AD. Factors correlated with cerebrovascular and neurological impairment, including history or morbidity of cerebrovascular and metabolic disease, lifestyle, as well as genetic variants, may affect the risk of vascular dementia $(\mathrm{VaD})$ [8]. The mechanisms might be related either to subcortical vascular lesions or to the lack of compensatory functional cortical changes [9]. The term vascular cognitive impairment (VCI) was proposed to recognize the cognitive alterations caused by vascular factors, while vascular dementia (VaD) refers to the most severe form of VCI [10]. According to Vascular Impairment of Cognition Classification Consensus Study (VIC$\mathrm{CCS}$ ) guideline [11], major VCI (or VaD) is diagnosed with clinically significant deficits in at least 1 cognitive domain that cause a severe disruption of activities of daily living. While mild VCI refers to impairment in at least one cognitive domain but mild to no impairment in activities of daily living [11]. This new definition aligns with revised terminology in DSM-V, which distinguishes between major and minor neurocognitive disorders [8]. It has been reported that depression appeared to be common prior to the onset of vascular dementia due to mood effects caused by ischemic damage on frontal corticalsubcortical circuits, recognized as vascular depression (VD). VD is closely related to cognitive impairment and cerebrovascular pathology. It might have neurophysiological impact on deterioration of cognitive functions, as well as on specific cortical circuits in subcortical vascular disease. For example, white matter lesions (WMLs) are more common and severe in patients with depression [12].

Detailed clinical diagnosis of cognitive impairment is a complex process involving multidimensional assessment of neurophysiological parameters and mental abilities [3]. In practical situations, cognitive testing is more often accomplished using validated screening instrument, such as MMSE [13] or MoCA [14]. Still, the screening and testing of cognitive impairment in practical clinical conditions are insufficient therefore require more auxiliary methods.

Cerebral imaging technique such as brain Magnetic Resonance Imaging (MRI) is required for clinical diagnosis of vascular cognitive impairment (VCI) [15]. Previous studies have indicated the correlations between cerebral vascular imaging appearance with cognitive functions $[16,17]$. It has been suggested that vascular brain injury (VBI) imaging indications, such as white matter hyperintensities (WMH) and perivascular spaces (PVS) burdens were associated with higher risk of dementia [18]. The leukoaraiosis and disability (LADIS) study is a European multicenter collaboration started in 2001 aiming at assessing the value of white matter changes (WMC) in predicting disability in elders. The main results of the LADIS study have demonstrated that severe WMC predicted decline of cognitive and motor performances, depressive symptoms associated with aging and cerebrovascular diseases $[19,20]$.. Markers of cerebral SVD can be individually assessed on brain MRI imaging. However, a total SVD burden score might capture the overall effect of SVD on the brain better than by considering individual features separately. In a most recent analysis of LADIS cohort, it was suggested that a combined measure of global burden of small vessel disease-related brain changes, which extracted with automatic imaging segmentation, was associated with VCI [21]. Yet, a practical comprehensive evaluation system for cerebrovascular imaging is still lacking.

Recently, a pragmatic estimate of total cerebral SVD burden were developed by summing the presence of silent SVD MRI markers including asymptomatic lacunar infarcts, white matter lesions, cerebral microbleeds, and enlarged perivascular spaces, yielding a 0 to 4 "total SVD score" [22]. The scoring system (CSVD score) captures the overall effect of CSVD on the brain, rather than estimating only one or two individual CSVDs separately [23]. This total SVD score was associated with blood pressure and cognition [24], as well as linked with risk factors for CSVD and with cognitive dysfunction in lacunar stroke patients, and it might be helpful for the rapid quantification or stratification of CSVD [22]. It has been shown that imaging changes in cerebral small vessel disease under the cortex are also associated with increased 
incidence of AD [25]. And the correlation between CSVD and cognitive impairment in stroke patients have also been reported [26]. However, analysis of the correlation between these imaging features and cognitive functions in general elder populations are still few.

In current study, based on a hypothesis that cerebral vascular characteristics are correlated with cognitive impairment, we performed a community based study, aiming to explore the correlation between cerebral vascular imaging features (including lacunes, new small subcortical infarct, enlarged perivascular spaces (EPVS), severity of white matter hyperintensities (WMH), cerebral microbleeds (CMBs), and total MRI score of CSVD) with cognitive functions in elder Chinese population.

\section{Method}

\section{Study design and subjects}

This was a cross-sectional study in community setting aiming to assess the prevalence, risk factors and correlation with cerebral small vessel disease appearance of cognitive impairment in elder residents. From October 2017 to September 2018, elder residents were recruited through on-site visit of 6 communities in Shanghai, China, including:

- Jinze Community, No. 271, Nurture Road, Jinze Town, Qingpu District, Shanghai, China;

- Xujing Community: No. 1088, Xumin Road, Xujing Town, Qingpu District, Shanghai, China

- Xianghuaqiao Community: No.1, Lane 1195, Xinqiao Road, Qingpu District, Shanghai, China

- Daying Community, Xianghuaqiao Street, Qingpu District, Shanghai, China;

- Huaxin Community: 800 Huazhi Road, Huaxin Town, Qingpu District,Shanghai, China;

- Liantang Community: No. 3619, Zhufeng Road, Liantang Town, Qingpu District, Shanghai, China;

- Shenxiang Community: No 39 Quchi Road, Zhujiajiao Town, Qingpu District, Shanghai, China;

Each community were with a population from 40,000 to 200,000. Briefly, flyers and other forms of notices were distributed with the help of neighborhood committees in each community in a period of 2 weeks before an on-site public free health consulting for elder people was given in each community. The attendants of all the event were registered and then 300 participants within the stage age requirement without reported significant diseases were randomly selected and further recruited by a door-todoor visit.

The participants were considered eligible if they have a permanent resident status in Qingpu district, age $\geq 60$ years, volunteered to join the study and sign the informed consent. The excluded individuals were those with a history of stroke or diagnosed dementia; history of brain-related diseases such as brain tumors and hydrocephalus; small blood vessel related white matter lesions such as multiple sclerosis; MR contraindications such as cardiac implant pacemakers, implantable defibrillators, cardiac stents, cochlear and other metal implants, claustrophobia; those who were unable to cooperate independently to complete the study; and other serious physical and mental illnesses that may lead to loss of follow-up.

The participants underwent examinations including brain MRI, laboratory tests of blood and urine samples, as well as questionnaire surveys of cognitive functions. All participant signed informed consent form and the study was approved by the Ethical Committee of Zhongshan Hospital affiliated to Fudan University, Qingpu Branch (2017-30).

\section{Subjects assessment}

Cognitive function was evaluated with Mini-Mental State Examination (MMSE) [27]. The validity and reliability of Chinese version of MMSE has been verified previously [28]. The MMSE scale is composed of a total of 30 items, including instant memory, delayed recall, attention and computational power, orientation, object naming, reading comprehension, speech comprehension, language retelling, speech expression, and visual space ability, with each item score 1 point, and 1 extra point added if the patient's education years are $\leq 12$ years. Cognitive impairment was categorized as following: $25-30$, none; $20-25$, mild; $10-20$; moderate; $0-10$, severe. A cutoff of $\leq 24$ points was used as recognition of cognitive impairment $[27,29]$.

\section{Brain MRI assessment of small vessel disease status}

All patients underwent routine $\mathrm{T} 1$ weighted image (T1WI), T2 weighted image (T2WI), Diffusion-weighted imaging (DWI), Fluid-attenuated inversion recovery imaging (FLAIR), and Susceptibility weighted imaging (SWI) examinations using the Umr770 (3.0 T) MRI. The SWI parameter settings were: deflection angle $15^{\circ}$; repetition time $30 \mathrm{~ms}$; echo time $20 \mathrm{~ms} ; 230 \mathrm{~mm} \times 230 \mathrm{~mm}$ field of view; matrix $448 \times 380 ; 1 \mathrm{~mm}$ layer with $1 \mathrm{~mm}$ layer spacing.

All imaging changes related to CSVD (cerebral small vessel disease) were defined according to the 2012 standard for the evaluation of statistical changes in imaging [30]:

- Lacunes: Cystic lesions with a diameter of 3-15 mm, with low signal on T1WI and FLAIR images, and high signal on T2WI images. 
- New small subcortical infarct: A high-signal lesion with a diameter of 3-20 mm on DWI.

- Enlarged Perivascular Spaces (EPVS): cystic lesions $<3 \mathrm{~mm}$ in diameter, with low signal on T1-weighted images and FLAIR images, and high signal on T2-weighted images.

- Severity of white matter hyperintensities (WMH) was assessed using the Fazekas scale [31]: 1) Score of ventricular high signal score: 0 point: no lesions; 1 points: cap-like or pencil-like thin layer lesions; 2 points: the lesion shaped as a smooth halo; 3 points: irregular high signal around the ventricle, extending to the deep white matter. 2) Deep white matter signal: 0 points: no lesions; 1 points: point lesions; 2 points: lesions begin to fuse; 3 points: large area fusion of lesions.

- Cerebral microbleeds (CMBs): a. GRE-T2"WI or SWI sequence with low signal loss; b. Round or oval; c. Clear border; d. Small volume (2 to $5 \mathrm{~mm}$ ) Or 2 to $10 \mathrm{~mm}$ ); e. At least $1 / 2$ of the lesion is surrounded by the brain parenchyma.

- MRI score of CSVD [22]: 1) WML: Fazekas scale $\geq 2$ points, add 1 point; 2 ) sulcus $\geq 1$, add 1 point; 3 ) deep CMBs $\geq 1$, add 1 point; 4) basal ganglia EPVS $>10$, add 1 points; total score $0-4$.

\section{Clinical and laboratory variables}

We collected the participant's data including basic demographic information, disease history, family history, smoking and drinking status. The medical conditions of participants including current comorbidity and medications were also collected. In addition, participants were asked to voluntarily take physical examinations and laboratory tests of blood and urine samples to assess traditional risk factors of cognitive impairment/cerebral vascular diseases.

Carotid ultrasonography was performed on each participant to measure the carotid artery intima-media thickness, as previously described [32].

\section{Statistical analyses}

Statistical analyses were performed using the Windows SPSS software package (version 20.0, IBM Corporation, Armonk, NY, USA). The differences between baseline characteristics and cerebral vessel characteristic parameters were compared between patients with and without cognitive impairment, with the Mann-Whitney $U$ test used to compare continuous variables, and Fisher's exact test or the chi-square test used to compare categorical variables, as appropriate. As exploratory analysis for penitential correlated factors of cognitive functions, multivariate linear correlation test was performed to detect association between baseline and cerebral vascular characteristics with MMSE score. To determine the risk factors of cognitive impairment, multivariate binary logistic regression test was applied to identify independent correlating factors for cognitive impairment. A probability value of $p<0.05$ was considered statistically significant.

\section{Results \\ Participants}

After screening with eligible criteria, total 171 subjects completed survey and examinations. There were 48 participants diagnosed with mild, 7 with moderate cognitive impairment, with a total percentage of $32.2 \%$.

As shown in Table 1, participants with cognitive impairment showed significant differences in age, BMI, education level and labor status. Cognitive impaired participant were also identified with higher level of HDL and UCR, and lower levels of full blood count (FBC) and AST/ALT. These results indicated that the cognitive impairment may be associated with other comorbidities or health conditions.

The cerebral vascular imaging parameters were also compared between participants with and without cognitive impairments. A significant difference was detected in CSVD score (Table 2).

Linear correlations with MMSE cognitive function score have been often utilized to explore potential risk factors of cognitive impairment [33, 34]. To further explore the association of cognitive function with cerebral vascular imaging parameters, linear regression analysis was performed between MMSE score and imaging parameters. As shown in Table 3, significant correlations were detected between MMSE score and both left and right carotid artery peak systolic velocity (PSV) score. However, the CSVD score was only borderline $(P=0.0566)$ correlated with MMSE. Multivariate correlation analysis including all collected risk factor data (Table 4) showed that left carotid artery PSV score was among the independent correlated factors of MMSE. In addition, MMSE was significantly associated with age, gender, marital status, education, income, smoking status, history and medication of hypertension and hyperlipidemia, history of peripheral artery disease (PAD) and coronary heart disease (CHD).

Although significant linear correlations with MMSE score has been identified in several factors, when participants were categorized as with or without cognitive impairment according to MMSE score, multivariate binary logistic analysis showed that age, education and history of hypertension were the only statistically independent associated factors of cognitive impairment (Table 5). 
Table 1 Demographic and clinical data of participants with different level of cognitive impairment

\begin{tabular}{|c|c|c|c|c|}
\hline Characteristics & & No $(n=116)$ & Yes $(n=55)$ & $P$ value \\
\hline & Age (years); Mean $\pm S D$ & $67.1 \pm 4.7$ & $69.3 \pm 5.1$ & 0.006 \\
\hline \multirow[t]{39}{*}{ Demographic } & Gender (n) & & & 0.168 \\
\hline & Male & 53 & 19 & \\
\hline & Female & 63 & 36 & \\
\hline & BMI; Mean \pm SD & $23.7 \pm 2.8$ & $22.1 \pm 2.2$ & 0.001 \\
\hline & Marriage status; $\mathrm{n}$ & & & 0.034 \\
\hline & Married & 109 & 45 & \\
\hline & Divorced & 2 & 2 & \\
\hline & Widowed & 5 & 8 & \\
\hline & Living status; $\mathrm{n}$ & & & 0.215 \\
\hline & Alone & 5 & 2 & \\
\hline & With spouse & 14 & 12 & \\
\hline & With children & 70 & 34 & \\
\hline & With both & 27 & 7 & \\
\hline & Education level; $\mathrm{n}$ & & & 0.015 \\
\hline & College & 2 & 0 & \\
\hline & High school & 11 & 2 & \\
\hline & Middle school & 34 & 8 & \\
\hline & Elementary school & 51 & 26 & \\
\hline & None & 18 & 19 & \\
\hline & Income (Yuan/per month); n & & & 0.586 \\
\hline & $<1000$ & 2 & 3 & \\
\hline & $1000 \sim 2999$ & 74 & 31 & \\
\hline & $3000-4999$ & 29 & 16 & \\
\hline & $>5000$ & 10 & 5 & \\
\hline & 5 & 1 & 0 & \\
\hline & Labor status in work; n & & & 0.040 \\
\hline & Mild & 52 & 14 & \\
\hline & Moderate & 60 & 38 & \\
\hline & Heavy & 3 & 3 & \\
\hline & Smoke status; $\mathrm{n}$ & & & 0.224 \\
\hline & None & 71 & 42 & \\
\hline & Mild & 1 & 1 & \\
\hline & Moderate & 24 & 6 & \\
\hline & Heavy & 19 & 6 & \\
\hline & Drinking & & & 0.212 \\
\hline & None & 79 & 43 & \\
\hline & Mild & 17 & 9 & \\
\hline & Moderate & 15 & 2 & \\
\hline & Heavy & 5 & 1 & \\
\hline \multirow[t]{9}{*}{ Medical conditions } & Hypertension; n & & & 0.782 \\
\hline & Missing & 2 & 1 & \\
\hline & No & 36 & 20 & \\
\hline & Yes & 78 & 34 & \\
\hline & Hyperlipidemia; n & & & 0.367 \\
\hline & Missing & 1 & 1 & \\
\hline & No & 89 & 48 & \\
\hline & Yes & 20 & 6 & \\
\hline & Unknown & 3 & 0 & \\
\hline
\end{tabular}


Table 1 (continued)

\begin{tabular}{|c|c|c|c|c|}
\hline \multicolumn{2}{|l|}{ Characteristics } & \multirow{2}{*}{ No $(n=116)$} & \multirow[t]{2}{*}{ Yes $(n=55)$} & \multirow{2}{*}{$\frac{P \text { value }}{0.225}$} \\
\hline & Diabetes; n & & & \\
\hline & Missing & 0 & 1 & \\
\hline & No & 80 & 41 & \\
\hline & Yes & 36 & 13 & \\
\hline & TIA; n & & & 0.258 \\
\hline & Missing & 1 & 2 & \\
\hline & No & 109 & 53 & \\
\hline & Carotid stenosis; n & & & 0.219 \\
\hline & Missing & 1 & 2 & \\
\hline & No & 110 & 53 & \\
\hline & Yes & 3 & 0 & \\
\hline & Brain trauma; $\mathrm{n}$ & & & 0.425 \\
\hline & Missing & 1 & 2 & \\
\hline & No & 110 & 52 & \\
\hline & Yes & 3 & 1 & \\
\hline & $P A D ; n$ & & & 0.682 \\
\hline & Missing & 1 & 1 & \\
\hline & No & 112 & 53 & \\
\hline & Yes & 1 & 1 & \\
\hline & $C V D ; n$ & & & 0.466 \\
\hline & Missing & 1 & 2 & \\
\hline & No & 107 & 52 & \\
\hline & Yes & 2 & 1 & \\
\hline & $A F ; n$ & & & 0.346 \\
\hline & Missing & 1 & 2 & \\
\hline & No & 114 & 53 & \\
\hline & Yes & 1 & 0 & \\
\hline & Chronic renal insufficiency; $\mathrm{n}$ & & & 0.148 \\
\hline & Missing & 1 & 2 & \\
\hline & No & 115 & 52 & \\
\hline & Yes & 0 & 1 & \\
\hline & Gout/high uric acid; $n$ & & & 0.434 \\
\hline & Missing & 1 & 2 & \\
\hline & No & 113 & 52 & \\
\hline & Yes & 2 & 1 & \\
\hline & Tumor; n & & & 0.217 \\
\hline & Missing & 1 & 2 & \\
\hline & No & 112 & 53 & \\
\hline & Yes & 3 & 0 & \\
\hline \multirow{10}{*}{$\begin{array}{l}\text { Physical conditions and laboratory } \\
\text { examinations }\end{array}$} & $\mathrm{HR} ;$ Mean $\pm \mathrm{SD}$ & $81.3 \pm 77.2$ & $78.8 \pm 9.7$ & 0.812 \\
\hline & $\mathrm{SBP} ;$ Mean \pm SD & $128.8 \pm 12.0$ & $128.6 \pm 10.1$ & 0.895 \\
\hline & DBP; Mean \pm SD & $77.8 \pm 7.6$ & $77.3 \pm 8.5$ & 0.683 \\
\hline & Hcy; Mean \pm SD & $16.2 \pm 5.0$ & $15.3 \pm 5.1$ & 0.274 \\
\hline & Cholesterol; Mean \pm SD & $5.2 \pm 0.89$ & $5.2 \pm 0.61$ & 0.901 \\
\hline & Triglyceride; Mean \pm SD & $1.7 \pm 0.91$ & $1.8 \pm 0.74$ & 0.696 \\
\hline & $\mathrm{HDL} ;$ Mean $\pm \mathrm{SD}$ & $1.4 \pm 0.28$ & $1.5 \pm 0.24$ & 0.021 \\
\hline & LDL; Mean \pm SD & $3.2 \pm 0.84$ & $3.1 \pm 0.57$ & 0.844 \\
\hline & AST; Mean \pm SD & $28.8 \pm 10.6$ & $24.8 \pm 9.1$ & 0.016 \\
\hline & $\mathrm{ALT} ;$ Mean $\pm \mathrm{SD}$ & $31.0 \pm 9.2$ & $25.2 \pm 10.7$ & $<0.0001$ \\
\hline
\end{tabular}


Table 1 (continued)

\begin{tabular}{|c|c|c|c|c|}
\hline Characteristics & & No $(n=116)$ & Yes $(n=55)$ & $P$ value \\
\hline & Cystatin C; Mean \pm SD & $0.98 \pm 0.57$ & $0.86 \pm 0.18$ & 0.135 \\
\hline & Creatinine; Mean \pm SD & $64.1 \pm 14.7$ & $65.5 \pm 15.3$ & 0.586 \\
\hline & Uric acid; Mean \pm SD & $336.2 \pm 67.9$ & $346.9 \pm 60.3$ & 0.323 \\
\hline & $\mathrm{FBC} ;$ Mean $\pm \mathrm{SD}$ & $6.3 \pm 1.7$ & $5.5 \pm 1.1$ & 0.001 \\
\hline & $\mathrm{HbA1c}$; Mean $\pm \mathrm{SD}$ & $6.0 \pm 1.2$ & $6.3 \pm 6.9$ & 0.661 \\
\hline & CRP; Mean $\pm S D$ & $1.8 \pm 2.6$ & $1.8 \pm 0.98$ & 0.902 \\
\hline & UCR; Mean \pm SD & $11.1 \pm 6.3$ & $15.2 \pm 8.7$ & 0.001 \\
\hline & MA; Mean \pm SD & $33.1 \pm 40.7$ & $26.7 \pm 26.1$ & 0.290 \\
\hline & UACR; Mean \pm SD & $22.8 \pm 24.1$ & $25.9 \pm 22.0$ & 0.429 \\
\hline
\end{tabular}

TIA Transient ischemic attack, PAD Peripheral artery disease, CHD Coronary heart disease, AF Atrial fibrillation, HR Heart rate, SBP Systolic Blood Pressure, DBP Diastolic blood pressure, Hcy Homocysteine, HDL High-density lipoprotein, LDL Low-density lipoprotein, AST Aspartate aminotransferase, ALT Alanine aminotransferase, FBC Full blood count, HbA1c Hemoglobin A1c, CRP C-reactive protein, UCR Urine Creatinine, MA Microalbumin, UCAR Urine albumin-to-creatinine ratio

\section{Discussion}

The results in this study showed that there was a significant prevalence of cognitive impairment in the elder population of communities in Qingpu District, Shanghai, China. Age, education, vascular and metabolic disease histories were the common risk for cognitive impairment. Correlations between cerebral vascular imaging parameters, including left and right carotid artery PSV (perivascular spaces) score, and CSVD with cognitive functions have been detected in various settings, with the strongest association found between left carotid artery PSV and MMSE. However, the CSVD score was not statistically significant in recognition of cognitive impairment.

Cognitive impairment is concerned in certain clinical settings such as post-stroke and atrial fibrillation (AF) patients [35]. In addition, it is a great risk factor of elder abuse [36]. This study was aiming mainly to evaluate associated between CVSD imaging characteristics with cognitive impairment, instead of a pure epidemiology

Table 2 Comparison between cerebral vascular imaging parameters between participants with different cognitive impairment

\begin{tabular}{llll}
\hline $\begin{array}{llll}\text { Parameters; } \\
\text { Mean } \pm \text { SD }\end{array}$ & \multicolumn{2}{l}{ Cognitive impairment } & P value \\
\cline { 2 - 3 } & No $(\boldsymbol{n}=\mathbf{1 1 6})$ & Yes $(\boldsymbol{n}=\mathbf{5 5})$ & \\
\hline LCCA-IMT & $0.752 \pm 0.092$ & $0.745 \pm 0.088$ & 0.6471 \\
LCCA-PSV & $6.27 \pm 2.51$ & $6.02 \pm 1.25$ & 0.4043 \\
RCCA-IMT & $0.741 \pm 0.088$ & $0.738 \pm 0.085$ & 0.8492 \\
RCCA-PSV & $6.15 \pm 2.71$ & $6.49 \pm 6.27$ & 0.6985 \\
LCA-psV & $5.12 \pm 3.23$ & $5.34 \pm 1.36$ & 0.5318 \\
RCA-psV & $5.64 \pm 5.32$ & $6.64 \pm 7.41$ & 0.3704 \\
CSVD & $1.59 \pm 1.47$ & $1.13 \pm 1.38$ & 0.0471 \\
\hline
\end{tabular}

LCCA-IMT Left common carotid artery intima-media thickness, LCCA-PSV Left common carotid artery peak systolic velocity, RCCA-IMT Right common carotid artery intima-media thickness, RCCA-PSV Right common carotid artery peak systolic velocity, LCA-psv Left carotid artery peak systolic velocity, RCA-psv Right carotid artery peak systolic velocity, CSVD Cerebral small vessel disease score estimation of VCI. The study was performed in Shanghai due to cooperation with community enable a relative large regional population based study to be carried. This region in general may represent a population of Southeastern China population with relative better economic and educational levels. Although many studies have been reported on the prevalence of dementia in China, very few was on mild cognitive impairment. Most of these studies have been performed in isolated regions therefore the results showed a broader range of variations. Meta-analysis of 96 observational studies reported that the overall prevalence of dementia in Chinese people aged 60 years and older was $5 \cdot 30 \%$, higher in rural populations, probably due to the lower educational level. Age and sex also affect dementia prevalence. The prevalence of dementia is higher in Western China and northern China compared to southern China. The prevalence of mild cognitive impairment was reported to be $12 \cdot 7 \%$ for individuals aged 60 years and older across all of the regions. Vascular-related mild cognitive impairment subtypes were the most common (42\%) in individuals aged 65 and older. Lower educational level, women and rural area residences were associated with higher prevalence of cognitive impairment [7, 31, 37, 38].. In this study, we identified more than $30 \%$ participants with mild and moderate cognitive impairment. In addition, significant percentage of participants in the current study had vascular or metabolic disease history. These results indicate that most the participant may have certain concerns in health status therefore the estimated prevalence of cognitive impairment might have been magnified.

The scope of the current report was to identify whether the vertebral vessel imaging characteristics was correlated with cognitive impairment in general elder population. The MMSE was selected as easy tool for cognitive function evaluation. The other neurological 
Table 3 Univariate linear correlation test between MMSE score and cerebral vascular disease status

\begin{tabular}{|c|c|c|c|c|c|c|c|c|c|}
\hline & & mmse & LCCA-IMT & LCCA-PSV & RCCA-IMT & RCCA-PSV & LCA-psv & RCA-psv & CSVD \\
\hline \multirow[t]{2}{*}{ mmse } & Coefficient & 1.0000 & 0.0014 & 0.0068 & -0.0190 & 0.0165 & -0.1700 & -0.1820 & 0.1465 \\
\hline & $P$ value & & 0.9860 & 0.9298 & 0.8055 & 0.8313 & 0.0264 & 0.0172 & 0.0566 \\
\hline \multirow[t]{2}{*}{ LCCA-IMT } & Coefficient & 0.0014 & & 0.0083 & 0.7670 & -0.0250 & -0.0475 & -0.0282 & 0.1061 \\
\hline & $P$ value & 0.9860 & & 0.9144 & $<0.0001$ & 0.7453 & 0.5370 & 0.7141 & 0.1672 \\
\hline \multirow[t]{2}{*}{ LCCA-PSV } & Coefficient & 0.0068 & 0.0083 & & -0.0678 & 0.6220 & 0.3610 & 0.3180 & 0.1199 \\
\hline & $P$ value & 0.9298 & 0.9144 & & 0.3783 & $<0.0001$ & $<0.0001$ & $<0.0001$ & 0.1184 \\
\hline \multirow[t]{2}{*}{ RCCA-IMT } & Coefficient & -0.0190 & 0.7670 & -0.0678 & & -0.0381 & -0.0370 & -0.0462 & 0.0700 \\
\hline & $P$ value & 0.8055 & $<0.0001$ & 0.3783 & & 0.6206 & 0.6313 & 0.5489 & 0.3630 \\
\hline \multirow[t]{2}{*}{ RCCA-PSV } & Coefficient & 0.0165 & -0.0250 & 0.6220 & -0.0381 & & 0.3190 & 0.3850 & 0.0577 \\
\hline & $P$ value & 0.8313 & 0.7453 & $<0.0001$ & 0.6206 & & $<0.0001$ & $<0.0001$ & 0.4539 \\
\hline \multirow[t]{2}{*}{ LCA-psv } & Coefficient & -0.1700 & -0.0475 & 0.3610 & -0.0370 & 0.3190 & & 0.0000 & -0.0780 \\
\hline & $P$ value & 0.0264 & 0.5370 & $<0.0001$ & 0.6313 & $<0.0001$ & & $<0.0001$ & 0.3108 \\
\hline \multirow[t]{2}{*}{ RCA-psv } & Coefficient & -0.1820 & -0.0282 & 0.3180 & -0.0462 & 0.3850 & 0.7060 & & -0.0802 \\
\hline & $P$ value & 0.0172 & 0.7141 & $<0.0001$ & 0.5489 & $<0.0001$ & $<0.0001$ & & 0.2970 \\
\hline \multirow[t]{2}{*}{ CSVD } & Coefficient & 0.1465 & 0.1061 & 0.1199 & 0.0700 & 0.0577 & -0.0780 & -0.0802 & \\
\hline & $P$ value & 0.0566 & 0.1672 & 0.1184 & 0.3630 & 0.4539 & 0.3108 & 0.2970 & \\
\hline
\end{tabular}

examination was not assessed in this study. This will certainly limit the detailed understanding about the relation between CSVD signs with different sections of cognitive functions. However, although the MMSE has significant limitations [39], it has been reported in LADIS study related cohort that MMSE scores were the only neuropsycological predictor of cognitive impairment in long term [40], indicating that a correlation with MMSE score may represents a relation with cognitive functions.

The results showed that although individual correlations between MMSE score with left carotid artery

Table 4 Independent correlated factors of MMSE identified with multivariate linear regression analysis

\begin{tabular}{llll}
\hline & B & t & P value \\
\hline Gender & 2.738973 & 2.405738 & 0.0186 \\
Age & -0.19572 & -3.40499 & 0.0011 \\
Marriage status & -1.39785 & -3.11385 & 0.0026 \\
Education level & -2.18476 & -6.35842 & $<0.0001$ \\
Income & -1.50688 & -3.49387 & 0.0008 \\
Smoke status & 1.539501 & 3.505515 & 0.0008 \\
Antihypertensive drugs & 0.070463 & 4.749113 & $<0.0001$ \\
Antilipid oxidant & -6.53721 & -2.60101 & 0.0112 \\
Hypertension & -5.21405 & -2.03592 & 0.0453 \\
Length of hypertension & -0.15209 & -3.66463 & 0.0005 \\
Hyperlipidemia & 0.517124 & 2.305949 & 0.0239 \\
Peripheral vascular disease & 7.042743 & 2.05852 & 0.0430 \\
Coronary heart disease & -5.06527 & -2.00128 & 0.0490 \\
LCA-psv & -0.63425 & -3.23109 & 0.0018 \\
\hline
\end{tabular}

(LCA)-psv, right carotid artery (RCA)-psv and CSVD score could be detected in various settings, the associations were not very strong. The only independent correlation between MMSE and these features were with LCA-psv in a linear regression analysis. CSVD score was not significantly associated with cognitive impairment. Since the study contain a relatively small sample size for multivariate analysis, and we did not perform any examination of $\mathrm{AD}$ symptom or biomarkers, therefore the negative results might have resulted from the limited statistical power. However, based on the results in univariate analysis, we would expect the association might be detected in a larger sample size and this is warranted in our future study.

Various results from LADIS studies initiated since 2001 have demonstrated the correlations between WMC with decline of cognitive and motor performances, depressive symptoms associated with aging and cerebrovascular diseases [19]., as well as with the presence of urinary disturbances, and various neurological abnormalities [20]. It was found that earlystage white matter lesions predict progressive cognitive

Table 5 Independent correlated factors of cognitive impairment identified with multivariate logistic regression analysis

\begin{tabular}{llll}
\hline & $\boldsymbol{P}$ value & $\operatorname{Exp}(\mathrm{B})$ & $\mathbf{9 5 \%} \mathrm{Cl}$ \\
\hline Age & 0.0022 & 1.2209 & $(1.0742,1.3876)$ \\
Education & 0.0002 & 4.3309 & $(1.9878,9.4359)$ \\
Hypertension & 0.0813 & 1.8195 & $(0.9282,3.5664)$ \\
Length of hypertension & 0.0387 & 1.1011 & $(1.0050,1.2064)$ \\
\hline
\end{tabular}


decline, indicating the importance of early recognition of small vessel disease and incipient vascular cognitive impairment [41], systematically checking for neurological examination abnormalities in older patients may be cost-effective in identifying high risk population [42]. In a recent reported LADIS related study, a combined measure of WMH, lacunar, gray matter, and hippocampal volumes, extracted by automatice imaging segmentation, was suggested to be able to serve as an imaging marker associated with vascular cognitive impairment [21]. Our results are in general consistent with these findings, and suggested that a systematic evaluation of cerebral VSD imaging markers may be important in screening the population at risk of VSI development.

The risk factors for dementia overlap with those for stroke, indicating shared pathological mechanisms [43]. The risk factors for both vascular and Alzheimer's dementia include increasing age, female sex as well as hypertension and diabetes [1]. There is also evidence linking cholesterol and obesity with elderly dementia [2, 44]. Smoking is linked to an increased risk of cognitive decline [45]. Cerebrovascular diseases are common risk factors for cognitive impairment. In this study, we observed that age, BMI, education level, disease history/comorbidity of hypertension and chronic renal insufficiency, and higher level of creatinine were among the potential correlated factors of cognitive impairment, which was consistent with previous studies. Multivariate linear analysis also detected the association between cognitive functions with traditional risk factors. However, only age, education and hypertension history were among the factors that may discriminate cognitive impairment. Again, these results might be due to the limited sample size and statistical power.

This study was subject to some limitations. First, as mentioned above, the sample size may have limited the statistical power of the multivariate analysis. In addition, many possible interactions among the risk factors exist, which may also interfere with statistical results. Furthermore, as a survey in community, the selection bias caused by the recruitment process and willingness of participants should always be considered.

\section{Conclusion}

In conclusion, the current study identified high prevalence of cognitive impairment in a Chinese community. In addition, correlations between cerebral vascular disease imaging status and cognitive functions were confirmed although the sample size limited the possibility of screening cognitive impairment with imaging technique.

\section{Abbreviations}

MMSE: Mini-Mental State Examination; CSVD: Cerebral small vessel disease; FBC: Full blood count; PSV: Peak systolic velocity; ALT: Alanine aminotransferase; PVD: Peripheral vascular disease; CHD: Coronary heart disease; $\mathrm{MCl}$ : Mild cognitive impairment; AD: Alzheimer's disease; VaD: Vascular dementia; VD: Vascular depression; VCI: Vascular cognitive impairment; VICCCS: Vascular Impairment of Cognition Classification Consensus Study; MRI: Magnetic Resonance Imaging; VBI: Vascular brain injury; WMH: White matter hyperintensities; PVS: Perivascular spaces; LADIS: Leukoaraiosis and disability; WMC: White matter changes; T1Wl:T1 weighted image; T2Wl:T2 weighted image; SWI: Susceptibility weighted imaging; DWI: Diffusion-weighted imaging; FLAIR: Fluid-attenuated inversion recovery imaging; EPVS: Enlarged Perivascular Spaces; CMBs: Cerebral microbleeds; PAD: Peripheral artery disease; CHD: Coronary heart disease; AF: Atrial fibrillation; LCA: Left carotid artery; RCA: Right carotid artery.

\section{Acknowledgements}

Not applicable.

\section{Authors' contributions}

WWW developed the concept and contributed to the study design and manuscript writing; YW, JX, LXL, LC and GW contributed to the data acquisition; $Y W$ analyzed the data; $H Y$ revised the manuscript. All have read the final version and have approved this submission.

\section{Funding}

This work was funded by Shanghai Qingpu District Health and Health Committee.

\section{Availability of data and materials}

All data generated or analysed during this study are included in this published article.

\section{Declarations}

Ethics approval and consent to participate

The study was approved by the Ethical Committee of Zhongshan Hospital affiliated to Fudan University, Qingpu Branch (2017-30).

\section{Consent for publication}

All participant signed informed consent form.

\section{Competing interests}

The authors declare that they have no competing interests.

\section{Author details}

${ }^{1}$ Department of Neurology, Qingpu Branch of Zhongshan Hospital, Fudan University, 1158 Park East Road, Qingpu Town, Qingpu District, Shanghai 201700, China. ${ }^{2}$ Department of Radiology, Qingpu Branch of Zhongshan Hospital, Fudan University, 1158 Park East Road, Qingpu Town, Qingpu District, Shanghai 201700, China.

Received: 11 December 2019 Accepted: 16 November 2021

Published online: 11 December 2021

References

1. Livingston G, Sommerlad A, Orgeta V, Costafreda SG, Huntley J, Ames D, et al. Dementia prevention, intervention, and care. Lancet. 2017;390:2673-734. https://doi.org/10.1016/S0140-6736(17)31363-6.

2. Li M, Gao Y, Cui J, Li Y, Li B, Liu Y, et al. Cognitive impairment and risk factors in elderly people living in fluorosis areas in China. Biol Trace Elem Res. 2016;172:53-60. https://doi.org/10.1007/s12011-015-0568-0.

3. Hugo J, Ganguli M. Dementia and cognitive impairment: epidemiology, diagnosis, and treatment. Clin Geriatr Med. 2014;30:421-42. https://doi. org/10.1016/j.cger.2014.04.001.

4. Knopman DS, Petersen RC. Mild cognitive impairment and mild dementia: a clinical perspective. Mayo Clin Proc. 2014;89:1452-9. https://doi.org/ 10.1016/j.mayocp.2014.06.019. 
5. International AsD. World Alzheimer's report 2018. https://www.alz.co.uk/ research/world-report-2018. Accessed 7 May 2019. (2019)

6. Wallin A, Roman GC, Esiri M, Kettunen P, Svensson J, Paraskevas GP, et al. Update on vascular cognitive impairment associated with subcortical small-vessel disease. J Alzheimers Dis. 2018;62:1417-41. https://doi.org/ 10.3233/JAD-170803.

7. Jia L, Quan M, Fu Y, Zhao T, Li Y, Wei C, et al. Dementia in China: epidemiology, clinical management, and research advances. Lancet Neurol. 2020;19(1):81-92.

8. ladecola C, Duering M, Hachinski V, Joutel A, Pendlebury ST, Schneider JA, et al. Vascular cognitive impairment and dementia: JACC scientific expert panel. J Am Coll Cardiol. 2019;73:3326-44.

9. Pennisi M, Lanza G, Cantone M, Ricceri R, Spampinato C, Pennisi G, et al. Correlation between motor cortex excitability changes and cognitive impairment in vascular depression: pathophysiological insights from a longitudinal TMS study. Neural Plast. 2016;2016:8154969. https://doi.org/ 10.1155/2016/8154969.

10. Gorelick PB, Scuteri A, Black SE, Decarli C, Greenberg SM, ladecola C, et al. Vascular contributions to cognitive impairment and dementia: a statement for healthcare professionals from the american heart association/ american stroke association. Stroke. 2011;42:2672-713. https://doi.org/10. 1161/STR.0b013e3182299496.

11. Skrobot OA, Black SE, Chen C, DeCarli C, Erkinjuntti T, Ford GA, et al. Progress toward standardized diagnosis of vascular cognitive impairment: guidelines from the vascular impairment of cognition classification consensus study. Alzheimers Dement. 2018;14:280-92.

12. Verdelho A, Madureira S, Moleiro C, Ferro JM, O'Brien JT, Poggesi A, et al. Depressive symptoms predict cognitive decline and dementia in older people independently of cerebral white matter changes: the LADIS study. J Neurol Neurosurg Psychiatry. 2013;84:1250-4. https://doi.org/10.1136/ jnnp-2012-304191.

13. Devenney E, Hodges JR. The mini-mental state examination: pitfalls and limitations. Pract Neurol. 2017;17:79-80. https://doi.org/10.1136/pract neurol-2016-001520.

14. Nasreddine ZS, Phillips NA, Bedirian V, Charbonneau S, Whitehead V, Collin I, et al. The Montreal cognitive assessment, MoCA: a brief screening tool for mild cognitive impairment. J Am Geriatr Soc. 2005;53:695-9.

15. Atri A. Imaging of neurodegenerative cognitive and behavioral disorders: practical considerations for dementia clinical practice. Handb Clin Neurol. 2016;136:971-84

16. Banerjee G, Jang H, Kim HJ, Kim ST, Kim JS, Lee JH, et al. Total MRI small vessel disease burden correlates with cognitive performance, cortical atrophy, and network measures in a memory clinic population. J Alzheimers Dis. 2018;63:1485-97. https://doi.org/10.3233/ JAD-170943.

17. Smith EE, Beaudin AE. New insights into cerebral small vessel disease and vascular cognitive impairment from MRI. Curr Opin Neurol. 2018;31:3643. https://doi.org/10.1097/WCO.00000000000000513.

18. Debette S, Schilling S, Duperron MG, Larsson SC, Markus HS. Clinical significance of magnetic resonance imaging markers of vascular brain injury: a systematic review and meta-analysis. JAMA Neurol. 2019;76:8194. https://doi.org/10.1001/jamaneurol.2018.3122.

19. Poggesi A, Pantoni L, Inzitari D, Fazekas F, Ferro J, O'Brien J, et al. 2001-2011: a decade of the LADIS (Leukoaraiosis and DISability) study: what have we learned about white matter changes and small-vessel disease? Cerebrovasc Dis. 2011;32:577-88. https://doi.org/10.1159/ 000334498

20. Pantoni L, Fierini F, Poggesi A. Impact of cerebral white matter changes on functionality in older adults: an overview of the LADIS study results and future directions. Geriatr Gerontol Int. 2015;15(Suppl 1):10-6.

21. Jokinen H, Koikkalainen J, Laakso HM, Melkas S, Nieminen T, Brander A, et al. Global burden of small vessel disease-related brain changes on MRI predicts cognitive and functional decline. Stroke. 2020;51:170-8. https:// doi.org/10.1161/STROKEAHA.119.026170.

22. Klarenbeek P, van Oostenbrugge RJ, Rouhl RP, Knottnerus IL, Staals J. Ambulatory blood pressure in patients with lacunar stroke: association with total MRI burden of cerebral small vessel disease. Stroke. 2013;44:2995-9. https://doi.org/10.1161/STROKEAHA.113.002545.
23. Huo YC, Li Q, Zhang WY, Zou N, Li R, Huang SY, et al. Total small vessel disease burden predicts functional outcome in patients with acute ischemic stroke. Front Neurol. 2019:10:808.

24. Staals J, Makin SD, Doubal FN, Dennis MS, Wardlaw JM. Stroke subtype, vascular risk factors, and total MRI brain small-vessel disease burden. Neurology. 2014;83:1228-34. https://doi.org/10.1212/WNL.0000000000 000837.

25. Liu Y, Braidy N, Poljak A, Chan DKY, Sachdev P. Cerebral small vessel disease and the risk of Alzheimer's disease: a systematic review. Ageing Res Rev. 2018;47:41-8. https://doi.org/10.1016/j.arr.2018.06.002.

26. Liang Y, Chen YK, Liu YL, Mok VCT, Ungvari GS, Chu WCW, et al. Cerebral small vessel disease burden is associated with accelerated Poststroke cognitive decline: a 1-year follow-up study. J Geriatr Psychiatry Neurol. 2019;32:336-43. https://doi.org/10.1177/0891988719862630.

27. Folstein MF, Folstein SE, McHugh PR. "mini-mental state". A practical method for grading the cognitive state of patients for the clinician. J Psychiatr Res. 1975;12:189-98. https://doi.org/10.1016/0022-3956(75) 90026-6.

28. Lv X, Li W, Ma Y, Chen H, Zeng Y, Yu X, et al. Cognitive decline and mortality among community-dwelling Chinese older people. BMC Med. 2019;17:63.

29. Pezzotti P, Scalmana S, Mastromattei A, Di Lallo D. The accuracy of the MMSE in detecting cognitive impairment when administered by general practitioners: a prospective observational study. BMC Fam Pract. 2008;9:29.

30. Wardlaw JM, Smith EE, Biessels GJ, Cordonnier C, Fazekas F, Frayne R, et al. Neuroimaging standards for research into small vessel disease and its contribution to ageing and neurodegeneration. Lancet Neurol. 2013;12:822-38. https://doi.org/10.1016/S1474-4422(13)70124-8.

31. Wu YT, Ali GC, Guerchet M, Prina AM, Chan KY, Prince M, et al. Prevalence of dementia in mainland China, Hong Kong and Taiwan: an updated systematic review and meta-analysis. Int J Epidemiol. 2018;47:709-19. https://doi.org/10.1093/ije/dyy007.

32. Naqvi TZ, Lee MS. Carotid intima-media thickness and plaque in cardiovascular risk assessment. JACC Cardiovasc Imaging. 2014;7:1025-38. https://doi.org/10.1016/j.jcmg.2013.11.014.

33. Yagi S, Akaike M, Aihara K, Iwase T, Yoshida S, Sumitomo-Ueda Y, et al. High plasma aldosterone concentration is a novel risk factor of cognitive impairment in patients with hypertension. Hypertens Res. 2011;34:74-8. https://doi.org/10.1038/hr.2010.179

34. Alfaro-Acha A, Al Snih S, Raji MA, Kuo Y-F, Markides KS, Ottenbacher KJ. Handgrip strength and cognitive decline in older Mexican Americans. J Gerontol A Biol Sci Med Sci. 2006;61:859-65. https://doi.org/10.1093/ gerona/61.8.859.

35. Graff-Radford J, Madhavan M, Vemuri P, Rabinstein AA, Cha RH, Mielke $M M$, et al. Atrial fibrillation, cognitive impairment, and neuroimaging. Alzheimers Dement. 2016;12:391-8.

36. Dong $X$, Chen $R$, Simon MA. Elder abuse and dementia: a review of the research and health policy. Health Aff (Millwood). 2014;33:642-9. https:// doi.org/10.1377/hlthaff.2013.1261.

37. Jiang B, Zhang XP, Chen MF, Wang Z, Zhao MX, Chen BH, et al. A crosssectional study of inpatients with late stage of dementia in Southeast China and the associations between biochemical parameters and apolipoprotein E genotypes. Clin Interv Aging. 2018;13:159-63.

38. Zhang Y, Guan Y, Shi Z, Yue W, Liu S, Liu S, et al. Sex differences in the prevalence of and risk factors for cognitive impairment no dementia among the elderly in a rural area of northern China: a population-based cross-sectional study. Neuroepidemiology. 2019;52:25-31. https://doi.org/ 10.1159/000493141.

39. Bak TH, Mioshi E. A cognitive bedside assessment beyond the MMSE: the Addenbrooke's cognitive examination. Pract Neurol. 2007;7:245-9.

40. Madureira S, Verdelho A, Moleiro C, Santos C, Scheltens P, Gouw A, et al. White matter changes and cognitive decline in a ten-year follow-up period: a pilot study on a single-center cohort from the Leukoaraiosis and disability study. Dement Geriatr Cogn Disord. 2016;41:303-13. https://doi. org/10.1159/000447121.

41. Jokinen H, Gonçalves N, Vigário R, Lipsanen J, Fazekas F, Schmidt R, et al. Early-stage white matter lesions detected by multispectral MRI segmentation predict progressive cognitive decline. Front Neurosci. 2015;9:455. https://doi.org/10.3389/fnins.2015.00455. 
42. Poggesi A, Gouw A, van der Flier W, Pracucci G, Chabriat H, Erkinjuntti T, et al. Neurological abnormalities predict disability: the LADIS (Leukoaraiosis and DISability) study. J Neurol. 2014;261:1160-9. https://doi.org/10. 1007/s00415-014-7332-9.

43. Hachinski V. The convergence of stroke and dementia. Arq Neuropsiquiatr. 2018;76:849-52. https://doi.org/10.1590/0004-282×20180148.

44. Ren L, Zheng Y, Wu L, Gu Y, He Y, Jiang B, et al. Investigation of the prevalence of cognitive impairment and its risk factors within the elderly population in Shanghai, China. Sci Rep. 2018;8:3575.

45. Zhong G, Wang Y, Zhang Y, Guo JJ, Zhao Y. Smoking is associated with an increased risk of dementia: a meta-analysis of prospective cohort studies with investigation of potential effect modifiers. PLoS One. 2015;10:e0118333. https://doi.org/10.1371/journal.pone.0118333.

\section{Publisher's Note}

Springer Nature remains neutral with regard to jurisdictional claims in published maps and institutional affiliations. 